\title{
Turning Transfer Inside Out: The Affordances of Virtual Worlds and Mobile Devices in Real World Contexts for Teaching About Causality Across Time and Distance in Ecosystems
}

\section{Citation}

Grotzer, Tina A., Megan M. Powell, Katarzyna M. Derbiszewska, Caroline J. Courter, Amy M. Kamarainen, Shari J. Metcalf, and Christopher J. Dede. 2014. "Turning Transfer Inside Out: The Affordances of Virtual Worlds and Mobile Devices in Real World Contexts for Teaching About Causality Across Time and Distance in Ecosystems." Tech Know Learn 20 (1) (December 23): 4369. doi:10.1007/s10758-014-9241-5.

\section{Published Version}

doi:10.1007/s10758-014-9241-5

\section{Permanent link}

http://nrs.harvard.edu/urn-3:HUL.InstRepos:23578226

\section{Terms of Use}

This article was downloaded from Harvard University's DASH repository, and is made available under the terms and conditions applicable to Open Access Policy Articles, as set forth at http:// nrs.harvard.edu/urn-3:HUL.InstRepos:dash.current.terms-of-use\#OAP

\section{Share Your Story}

The Harvard community has made this article openly available.

Please share how this access benefits you. Submit a story.

\section{Accessibility}




\title{
Turning Transfer Inside Out: The Affordances of Virtual Worlds and Mobile Devices in Real World Contexts for Teaching about Causality Across Time and Distance in Ecosystems
}

\author{
Tina A. Grotzer, Megan M. Powell, Amy K. Kamarainen, \\ Caroline J. Courter, M. Shane Tutwiler, S. J. Metcalf, and Chris J. Dede
}

\author{
Author's Accepted Version \\ Technology, Knowledge, and Learning
}

Turning Transfer Inside Out: The Affordances of Virtual Worlds and Mobile Devices in Real World Contexts for Teaching About Causality Across Time and Distance in Ecosystems has been published in the following paginated issue of Technology, Knowledge and Learning: Volume 20, Issue 1 (2015), Page 43-69

The final publication is available at Springer:

http://www.springerlink.com/openurl.asp?genre=article\&id=doi:10.1007/s10758-014-9241-5 
Turning Transfer Inside Out: The Affordances of Virtual Worlds and Mobile Devices in

Real World Contexts for Teaching about Causality Across Time and Distance in Ecosystems

\begin{abstract}
Reasoning about ecosystems includes consideration of causality over temporal and spatial distances; yet learners typically focus on immediate time frames and local contexts. Teaching students to reason beyond these boundaries has met with some success based upon tests that cue students to the types of reasoning required. Virtual worlds offer an opportunity to assess what students actually do in a simulated context. Beyond this, mobile devices make it possible to scaffold and assess learning in the real world. Situating learning outside, in the target contexts, bypasses many of the challenges of transfer. A study investigated the learning of fifth and sixth graders $(n=38)$ while they used a virtual world called EcoMUVE, designed to support learning of ecosystems concepts and complex causal dynamics, and Mobile Broadband Device (MBDs) components, designed to assess and support learning and transfer in a real pond ecosystem. The experiences of two classes were contrasted as reference populations; one class participated in the MBD experience first, followed by the learning components in EcoMUVE; the other participated in EcoMUVE first, followed by the MBD components. Rich and triangulated data was collected to illuminate how students experienced and responded to the curriculum components. Both classes made learning gains in EcoMUVE. Students who completed EcoMUVE prior to their MBD experience transferred concepts to their pond explorations. Both classes made learning gains at the pond following the MBD support and revealed more expert reasoning about the importance of change over time and distant drivers in ecosystem dynamics.
\end{abstract}

Keywords mobile devices; field trips; transfer; Multi-User Virtual Environments; complex causality; systems dynamics; ecosystems dynamics; watersheds; spatial scale; change over time

\title{
1. Introduction
}

Reasoning about ecosystems dynamics includes consideration of causality over time and across spatial distances. Research shows that students often frame systems concepts in reductive forms (Jacobson 2001) that fail to capture complex dynamics (e.g. Grotzer and Basca 2003; Hmelo-Silver and Pfeffer 2004; Penner 2000; Raia 2008); learners typically constrain their consideration to the immediate time frame and to local contexts. Further, students often hold limited notions of the environmental concepts that embed complex causal features. For instance, they don't understand that watersheds are part of the broader ecological system that includes the surrounding land and that they can be expansive (Shepherdson, Wee, Priddy, Schellenberger, and Harbor 2007). They focus on timedelineated events when reasoning about ecosystems (Grotzer, Kamarainen, Tutwiler, Metcalf and Dede 2013) at the expense of noticing broader processes of steady state. Further, they miss the non-obvious and microscopic causes that offer potential mechanism information about what is going on (e.g. Hogan and Fishkeller, 1996) in instances when covariation patterns may not be fully informative.

How to help students learn to reason in more expert ways given the limitations of the classroom has prompted researchers to explore how technology can create new instructional possibilities. For instance, researchers have developed virtual worlds (Dede 2009), handheld devices (e.g. Klopfer and Yoon 2005), and representational tools using hypermedia (e.g. Hmelo-Silver, Marathe and Liu 2007) to model complex dynamics. Multi-user virtual environments (MUVEs) are 3-D graphical worlds that enable simulated immersive experiences where users move through the world interacting with digital objects, tools, and computer-based agents. Such programs show promise in helping students learn ecosystems and complex systems concepts (e.g. Danish, Peppler, Phelps, and Washington 2011; Grotzer et al., 2013; Hmelo-Silver et al. 2007; Metcalf, Kamarainen, Tutwiler, Grotzer, and Dede 2011). Further, mobile devices make it possible to situate learning in authentic contexts and augment reality by offering models and other representational support. As elaborated below, virtual reality and mobile devices that scaffold learning may be instrumental in overcoming the specific challenges of causal induction in a complex problem space such as ecosystems.

However, the promise of technology in addressing the challenges of learning causal complexity and systems reasoning cannot be fully realized through measures of ability that are highly cued. Formal assessments enable us to see what ability students can reveal in cued situations but don't illuminate whether students would reason about distal factors and extended time frames in relevant contexts without this cueing. However, knowing to enact such knowledge in relevant contexts is essential to using it the everyday world. Actionable knowledge that transcends time and spatial scales is not easily assessed in classrooms. Virtual worlds and using mobile devices to augment reality also offer promise here. Virtual worlds—as parameterized versions of the real world—reveal what 
students actually do in a simulated context and provide an approximation of what students might be sensitive to and carry forward into real world contexts. As elaborated below, transfer is typically envisioned as learning in a sequestered context such as school (initial learning) that is carried forth into the real world (transfer of learning). However, mobile devices can support initial learning in the real world, thus have the potential "to turn transfer inside out," considerably shifting the implications for instruction.

This paper reports on a case study examining the learning of fifth and sixth graders while using the affordances of a virtual world called EcoMUVE, designed to support learning about ecosystems concepts and complex causal dynamics, and Mobile Broadband Device (MBDs) components. The MBD components were designed to assess transfer of these concepts to real ecosystems and to then teach the concepts in the real world. Measures of student behavior within the EcoMUVE and the MBD experiences enabled assessment of how each component interacted with whether students brought forth spatial and temporal reasoning in relevant cued and uncued contexts. Two classes participated as reference populations making it possible to contrast their experiences; One class participated in the MBD experience first, followed by the learning components in EcoMUVE while the other participated in EcoMUVE, followed by the MBD components. Rich and triangulated qualitative and quantitative data was collected.

\subsection{Theoretical Framework: The Challenges of Causal Induction and Transfer}

From a theoretical stance based in the research on causal induction, reasoning about ecosystems provides significant challenges. The causal induction research focuses on how humans discern causality through a combination of noticing co-variation between causes and effects (Gopnik and Glymour 2002; Gopnik and Schulz 2007); relying upon knowledge of mechanisms (Atran 1995; Keil 1994), and considering trustworthy testimony (e.g. Harris 2002). In learning to reason across time and distance, each of these modes of causal induction introduces difficulties that interact with the information available. When causes and effects exist in separate temporal and spatial attentional frames (Grotzer and Tutwiler 2014), co-variation patterns escape notice. In these cases, mechanism knowledge and testimony may still enable us to construct the causal story (Grotzer and Solis 2014). However, mechanism knowledge is often difficult to discern. It may be non-obvious or microscopic, such as in the case of microbes, phosphates, nitrates, and dissolved oxygen, and is typically missed by students (Hogan and Fishkeller 1996). Offering access to all three information sources through representations in the virtual world and through augmented reality in the real world to increase the salience of each mode of causal induction, increases the likelihood that students will construct an understanding of the causal dynamics of ecosystems. Below, we explain how EcoMUVE and an MBD component called EcoMOBILE are designed to do so.

Using these understandings in service of being ecologically literate in the world necessitates transfer, yet the challenges of transfer constitute a well-studied problem in the cognitive and learning sciences (e.g. Day and Goldstone 2012). Effective transfer necessitates deep initial learning of the concepts and targeted effort towards extracting and applying them forward (e.g. Chi and Van Lehn 2012). The points of possible failure for transfer are many. The initial learning may not be deep and flexible and the concepts may remain wedded to the initial contexts in which they were learned. If they are abstracted, they will only be applied in forward-reaching transfer if an occasion to apply them is detected; the learner must detect the environmental cues that signal an opportunity to deploy the knowledge. Finally, the learner must be motivated or "elect" to see the application through - to actually use the knowledge within the context (Perkins and Salomon 2012). Perkins, Jay, and Tishman (1993) have framed the application part of the transfer equation as being about sensitivity to occasion to deploy the target form of thinking, the ability to enact the thinking, and the inclination to see it through. (See Figure 1.)

Virtual worlds and mobile devices have the capacity to move the contexts of initial instruction closer to those of the intended application target. Virtual worlds are replicas that minimize some noise and offer instructional affordances while keeping key elements of the world intact. Mobile devices can place instruction in the target context so that at least one instance of real world application is available to the learner. Thus, an instructional emphasis can be placed on deep initial learning. This is not to argue that learning about underlying causal structure from experiences in virtual worlds that closely simulate the real world is without challenges. Learners may get caught up in surface features or in dramatic and seductive details (Harp and Mayer 1998); the rich texture of these experiences can make discerning the underlying causal structure more difficult (e.g. Ratterman and Gentner, 1998). Goldstone and Sakamoto (2003) found that real world similarity in technology simulations may advantage lowerachieving students in initial learning at the same time that it disadvantages them for transfer of the concepts. However, teaching concepts within the target context justifies effort invested on initial learning. Presumably, one would still want to help learners extract the concepts to the extent that they can apply them forward to new ecosystems. As elaborated below, building reflective affordances into simulated and real world learning experiences 
that abstract the causal patterns within a rich context may help all students to achieve deep learning of the causal dynamics within that system, and to transfer the learning to systems more broadly.

[Insert Figure 1 About here.]

\subsection{How EcoMUVE and the MBDs are Designed to Facilitate Causal Induction and Transfer}

EcoMUVE is a virtual world that harnesses the affordances of technology to accomplish ecosystem understanding goals that are otherwise difficult to achieve. It invites learners to realize how causes can act across time and distance by enabling them: 1) to view outcomes and then travel back and forth in time to see how change occurred over time and; 2) to move across distances to realize co-variation relationships that otherwise would not be apparent. A brief description of EcoMUVE is included here. An elaborated description can be found in Metcalf et al. 2011. The EcoMUVE Pond Module includes a virtual pond and its local and distal surroundings, including an adjacent golf course and more distant housing development. A calendar tool enables students to visit the pond on different days. They explore the environment, find organisms, talk to other characters, and collect data on the water, weather, and population levels. An eutrophication scenario is simulated in which a fish die-off occurs due to the proximal cause of low dissolved oxygen concentrations in the pond during a warm and windless night and the ultimate cause of eutrophication driven by excessive fertilizer runoff followed by algae growth and decomposition. To fully understand the fish die-off, students must attend to distant drivers of change, for instance, fertilizer that was applied in the watershed and made its way into the pond, as well as to changes over time.

EcoMUVE is designed to support complex causal induction. Students collect data that is graphically represented over time enabling them to reason about the longer term patterns in the ecosystem and to envision the covariation patterns. A submarine enables them to shrink to a microscopic level to learn about mechanisms that would otherwise escape their attention. A series of "Learning Quests," brief on-line mini-modules, provide in-depth information about mechanisms such as phosphates, nitrates, the role of dissolved oxygen in the pond, and other variables. Further, testimony from characters in the world - trusted and not — encourages students to consider alternative explanations. These design principles are elaborated in Grotzer et al. 2013. Learning about ecosystems dynamics using these affordances should enable deeper initial learning. Given the many similarities between the virtual world and a real pond, it is also likely that this learning will be more easily transferred forward --cued by similarities between the real world and the context of initial learning in the virtual world and then mapped through the deeper understanding that the affordances engender.

Mobile Broadband Devices (MBDs) can enable instructional experiences that support effective complex causal induction in the context of the real world. For the purposes of the study described below, an "EcoMOBILE" experience was designed to support causal induction by placing testimony in the real world, connecting information over time, and enabling students to "see" covariation relationships despite large spatial gaps between the causes and effects. The experience was designed for the specific context and used the following virtual and augmented reality tools: 1) Virtual Binoculars: Students could visit hot-spots locally that enabled them to see water-monitoring stations distally in an upper reservoir (See Figure 2.) and to gain information from the water quality reports over time that detailed the chemical make-up of water flowing from that watershed; 2) Time Transporter: Students could transport visitors from the past to provide information about the pond over time. The visitors, in period garb, offered true narratives about the history of the pond. (See Figure 3.) By offering these tools while at the pond, it increases the salience of the information necessary to construct the complex causal dynamics. Students can: 1) construct the covariation relationship between distant causes and the effects that they see locally; 2) reason about non-obvious variables related to the water quality and; 3) see how changes over time affect the system. Together, these components invite deep initial learning about an important ecosystem with implications for the drinking water in the town; it circumvents the need to extract the concepts from classroom learning and map them to real world contexts.

\section{[Insert Figures 2 and 3 about here.]}

\subsection{Rationale for a Case Study of "Reference Populations"}

The study reported here investigated behavior in the virtual world as well as in the real world with affordances enabled by each technology. Given the in-depth nature of the research, it was conducted as a case study that used the concept of "reference populations" in order to illuminate through contrast the experiences of two different classroom populations. As we have written about elsewhere, (Grotzer, Solis, and Honey 2014), the concept of reference populations is borrowed from ecosystem science (e.g. Weathers, Strayer, and Likens, 2013). It is 
utilized when trying to understand the differences between two contrasting populations where the concept of a control group does not validly apply. It may consider the impact of particular interventions, opportunistic or not, and it recognizes that it is not possible to control the myriad of differences between authentic populations in authentic, complex contexts. Instead, an attempt is made to understand the dynamics within each population and to draw contrasts where possible. It is highly applicable to educational studies that necessarily involve many interacting variables.

A case study of reference populations was chosen given the nuanced texture of the data needed to illuminate how students behaved in the virtual and real environments and the specifics of the MBD design for the local ecosystem. It was expected that analyzing rich data would illuminate aspects of students' experience that would be lost in a larger, randomized control study but that would be important to the Design-Based Research (e.g. Barab and Squire, 2004) involved in studying the promise of mobile devices using virtual and augmented reality for learning and transfer. As more is understood about these instructional designs, different kind of studies should be conducted to further inform our understanding.

\subsection{Research Questions}

Rich data was collected in an effort to address the following research questions:

What patterns can be discerned in the evidence concerning students' learning about complex dynamics (change over time, spatial distance, and non-obvious variables) across and within the two classes on: 1) cued and;2) non-cued assessment opportunities...

a) ...in relation to learning from EcoMUVE only?

b) ....in relation to learning from EcoMOBILE only?

c) ....in relation to transfer between EcoMUVE and EcoMOBILE?

d) ... in relation to the combination of EcoMUVE and EcoMOBILE?

\section{Methods}

\subsection{Design}

A case study was conducted contrasting two combined $5^{\text {th }} / 6^{\text {th }}$ grade classes of 19 students in each class $(\mathrm{n}=$ 38) from a school in Cambridge, MA. The study was part of a larger set of Design-Based studies to learn about the instructional promise of the technologies. The students are middle to upper middle class with some ethnic diversity. The students were somewhat younger than similar studies conducted by the research team, but represented a unique opportunity because of the location of the school which is adjacent the pond that EcoMUVE was modeled upon. The students regularly visit the pond; most have taken three or more trips a year to the pond since Kindergarten, and according to their teacher, felt that they knew all there was to know about it. Both classes had the same science teacher. They participated in the following design: Students took formal pre-assessments about the importance of actions related to investigating causality over time and distance to understanding an ecological issue. Then each class participated in a two-week exploration of EcoMUVE with the following differences. In one class (EcoMUVE/MBD), when the students discovered a fish die-off in the virtual world after three days of open-ended exploration, they sought to investigate this ecological puzzle within the EcoMUVE using affordances built into the program to enable them to reason across time, space, and given non-obvious, microscopic variables. After completing their exploration of EcoMUVE, they were then given an opportunity to visit the pond across from the school using the MBDs with a program designed to support learning about causality across distance and time (EcoMOBILE). In the second class (MBD/EcoMUVE), after three days of open-ended exploration in EcoMUVE, when the students discovered the fish-die off, they visited the real pond using MBDs with the supporting program. Following this opportunity they resumed their exploration of EcoMUVE and investigated the puzzle of the fish dieoff using the affordances within EcoMUVE to help them reason across space, time, and about non-obvious variables. When each class discovered the fish die-off, prior to investigating what happened, they took an assessment about what they thought happened to the fish. Rich data was collected to develop case studies for each group. Each class took a formal post-assessment upon completion of the EcoMUVE. The MBD component was designed to begin and end with open-ended questions designed to assess how students thought about the real pond ecosystem before and after experiencing the supporting EcoMOBILE curriculum intervention in between. This design enabled comparison between the classes in how students approached: 1) the solution to EcoMUVE with or 
without the influence of the MBD experience and;2) the MBD experience with or without the benefit of having solved the puzzle within EcoMUVE requiring reasoning across spatial and temporal scales. The two classes were similarly diverse and had a similar range of learners at different levels. The teacher and two of the researchers filming the classes independently noted that while both classes were engaged, the EcoMUVE/MBD class was a more boisterous group, possibly due to the timing of science class. They typically had science in the afternoon most days while the other class had science in the morning.

[Insert Table 1 about here.]

\subsubsection{Intervention Components}

The EcoMUVE pond module was used differently than in other administrations, as follows. Typically, there are a set of activity sheets to guide students behavior and students are given roles in an attempt to frame how they observe within the virtual world. This administration was much less structured and employed a mediated constructivism in which student inquiry was guided by what they noticed in the virtual world and the teacher made suggestions when students raised particular questions or issues. Students worked in pairs to encourage conversation between them that could then be analyzed. Data was lost when one partner was absent and the other continued to explore the world but didn't articulate what s/he was doing or why.

The students explored the virtual pond environment collecting images of what organisms lived there and making observations in paper-based science notebooks. On the third day, they were introduced to the time traveling tool enabling them to discover the fish die-off. At this point, the students took an assessment about what they thought was going on and one of the classes then participated in the EcoMOBILE experience. The placement of EcoMOBILE after the fish die-off was to enable the researchers to qualitatively assess whether this class treated their further exploration in EcoMUVE differently than the class who did not have the EcoMOBILE experience infused at this point. The classes then continued with EcoMUVE using the affordances that enabled them to investigate covariation relationships across time and distance and to discover non-obvious variables. They collected data, filled out the data charts, and studied the resulting graphs to consider changes over time. Mapping between their observations in the simulated world and their data representations, they noticed patterns and relationships and documented ideas in their science notebooks. They used the learning quests to offer possible mechanism information for the covariation patterns that they found. They generated hypotheses about what happened to the fish and were guided to check their hypotheses against the available data, including observational, numerical, and graphical, and to push beyond their first explanations to come up with the most compelling explanations based upon the evidence and the patterns in the data. Following the conclusion of EcoMUVE, the students again completed the assessments. The students in the second class then participated in the EcoMOBILE experience. This offered the opportunity to compare how they approached their initial observations and the EcoMOBILE affordances in comparison to the first class.

EcoMUVE is based on the ecology of Black's Nook in Cambridge, MA, a small pond that sits beside Fresh Pond Reservoir, the water source for the City of Cambridge. It shares tributaries and offers an accessible area of study. The EcoMOBILE experience on the MBD was designed to attempt to impact the kinds of observations that students made about the pond and the kinds of questions that they asked; encouraging them to embed their observations of the pond in a longer time frame and to realize that the pond is a part of a much larger watershed.

First, the EcoMOBILE experience asked students to make and record their open-ended observations of the pond and surroundings. This enabled analysis of students' observations that were unsupported by MBD affordances and comparisons between the kinds of observations made by students in the EcoMUVE/MBD to the MBD/EcoMUVE class. Next, it engaged students in the learning components: the "Virtual Binoculars" to "see" the upper watershed (See Figure 2) and the "Time Transporter" to bring persons from the past into the present (see Figure 3). These persons offered information that was incongruous with what the students know about the pond; that in the early 1900's junk was thrown into the pond in an attempt to fill it in. Presently, it looks like a nature preserve and is treated with respect. Finally, the students were again asked to make and record their open-ended observations of the pond and surroundings. Each class spent 1.5 hours at the pond

The framing of the EcoMOBILE field trip fit with the best practices on environmental field trips outlined by Tal, Lavie, Alon and Morag (2014). The learning activities invited students to experience the environment and to learn from and with their peers and teachers as they interacted around these experiences. The teacher and field trip chaperones behaved as involved and knowledgeable guides and the MBD and teacher support engaged students in their discoveries in making sense of the "big story" behind the experience. 


\subsubsection{Data Sources}

Students participated in two formal assessments from related work: 1) The Action at a Distance and Change Over Time (ADCT) Inventory designed to assess complex causal understanding developed in connection with the Causal Learning in the Classroom Project. ${ }^{1}$ It has four parts and a total of 22 questions. Eighteen questions use a four level Likert Scale to assess how important students consider certain types of information to the possible solution of an ecological puzzle. Two questions involve the open-ended generation of hypotheses. A set of multiple choice questions juxtapose correct responses framed locally versus distally to assess for the possibility that students reveal a preference for one type of explanation over the other regardless of their knowledge. 2) The Ecosystems Causal Dynamics Assessment (ECDA), slightly modified from Grotzer et al. 2013 is closely aligned with EcoMUVE. It describes a fish die-off and asks for open-ended responses about what might have happened to the fish. It also asks a set of four questions on a Likert Scale to determine what investigations students believed were most important towards figuring out what happened and space to explain any of their answers that they believed needed clarification. In addition to formal pre- and post-test measures, rich data was collected including video and audiotape of student pairs; science journal notes; student interviews; teacher reflections; field observations; on-line data that students collected and log file data revealing how students moved through the virtual world.

\subsection{Analysis}

Student responses on the ECDA and ADCT Assessments $(n=38)$ were coded by two independent coders using a scheme developed in earlier work attaining reliability of .89 (Very Good) using Cohen's Kappa. Two coders who were not familiar with the differences between the two groups did a grounded analysis of the EcoMUVE data intensively analyzing approximately 24 hours of video, audio, and log-file data; coding for emergent categories in each pair of students. Narratives of the experiences of four student teams $(n=8)$ were developed along with mappings of students' movements within the EcoMUVE world and how they changed over time as students learned more about the environmental scenario. The log-file data, video, and audio transcriptions were mined to develop the narratives and to reveal the paths that students took through the EcoMUVE. Given the time intensive nature of this analysis, the paths of eight students in four pairs were analyzed, two from each reference population. The particular four groups were chosen for analysis based on the following criteria: they had permission to be videotaped; were present for all of the sessions so there was a full data set; and they represented a mix of boys and girls. A third person then checked the narratives and points that were corroborated by both coders were used in the narratives of student performance. The resulting mappings offer a sense of student movement, but not relative time spent in each area as this was harder to interpret cleanly given that the time stamps in the log-file data also included non-focused time and time focused on tasks other than investigating the fish die-off (announcements, time talking to a neighbor about their work, showing someone else how to do something in the MUVE, etc.) Students' explorations in specific zones were quantified to analyze where and how much students ranged in their exploration. For the EcoMOBILE experience, data was collected for ten pairs of students $(n=20)$ representing 10 students from each class, chosen based upon similar criteria as for the EcoMUVE narratives. The students were followed by a graduate student researcher with a video camera for the extent of the field trip. The students were also outfitted with an audio recorder. Similar analyses were carried out for this data set (15 hours of video), coding for emergent patterns that characterized students' observations as well as for observations related to spatial proximity, temporal relationships, and non-obvious variables.

\section{Results}

\section{a.1 Performance on Formal, Cued Assessments}

The formal assessments offer a sense of how students respond in a cued context. Due to its open-ended nature, the Ecosystems Causal Dynamics Assessment enables the students to frame their responses so that while it is cued, it offers information about what students assume is important to bring to the task. Students' assumptions on the pretest fit with the kinds of default patterns predicted by the earlier research (Grotzer, Tutwiler, Dede, Kamarainen and Metcalf 2011) revealing a tendency to focus on spatially local explanations across conditions. Students $(\mathrm{n}=38)$ gave significantly more spatially local than distal responses on pretest $(68 \%$ v. $32 \%$, respectively,

\footnotetext{
${ }^{1}$ Accessed at http://gse.harvard.edu/uclab/
} 
Local (SLoc): $\underline{\mathrm{M}}=1.95, \underline{\mathrm{SD}}=.80$; Distal (SDist): $\underline{\mathrm{M}}=0.95, \underline{\mathrm{SD}}=.69, \underline{\mathrm{t}}(37)=4.76, \underline{\mathrm{p}}=0.0001$ (SDistPre $=1.77$ 0.43 SLocPre $)$ and as would be expected, are negatively correlated $(r=-0.49, n=38, \mathrm{p}<.0001)$. The two groups were equal upon expectation on the pretest (EcoMUVE/MBD Local: $\underline{\mathrm{M}}=2.1, \underline{\mathrm{SD}}=.81$, Distal: $\mathrm{M}=0.95, \underline{\mathrm{SD}}=$ 0.77; MBD/EcoMUVE: Local: $\underline{\mathrm{M}}=1.8, \underline{\mathrm{SD}}=0.79$, ns; Distal: $\underline{\mathrm{M}}=0.95, \underline{\mathrm{SD}}=0.62$, ns). Both groups showed a clear shift on the post-test towards balanced responses that suggest a greater appreciation for the possibility that causes could be local or distal ( $45 \%$ v 55\%, respectively, Local (SLoc): $\underline{\mathrm{M}}=0.73, \underline{\mathrm{SD}}=.98$; Distal (SDist): $\underline{\mathrm{M}}=.89$, $\underline{\mathrm{SD}}=.76, \underline{\mathrm{t}}(37)=-0.63, \mathrm{p}=\mathrm{ns})$ indicating that students used each type of explanation without a tendency to favor local explanation. (See Table 2 and Figure 4.) These shifts are attributable to the EcoMUVE because the assessments were given prior to the MBD in the EcoMUVE/MBD group so if adding the MBD experience had a discernible impact on these measures, we would expect to see differences between the groups. No discernable differences were found between the classes on the post-test (EcoMUVE/MBD Local: $\underline{\mathrm{M}}=0.63$, $\underline{\mathrm{SD}}=.83$, Distal: $\underline{\mathrm{M}}$ $=0.89, \underline{\mathrm{SD}}=0.81 ; \mathrm{MBD} / \mathrm{EcoMUVE}:$ Local: $\underline{\mathrm{M}}=0.84, \underline{\mathrm{SD}}=1.11 ;$ Distal: $\underline{\mathrm{M}}=0.89, \underline{\mathrm{SD}}=0,74$, Local: $\mathrm{R}^{2} \mathrm{Adj}=-$ 0.01, ns, Distal: $\left.\mathrm{R}^{2} \mathrm{Adj}=-0.02, \mathrm{~ns}\right)$.

[Insert Table 2 and Figure 4 about here.]

The second formal assessment, the ADCT inventory, is highly cued, explicitly asking students to respond to the relative important of distance and time in thinking about ecosystem puzzles. The post-tests here showed subtle shifts in increased recognition of the importance of considering a longer time span and more distant drivers of change, both within and across classes with no discernable differences between the classes. (See Figures 5-8).

[Insert Figures 5-8 about here.]

Given the very small sample size and that the students were clustered within classes, we interpret these descriptive statistics and outcomes as suggestive only and look to the qualitative outcomes to more fully understand the experiences of the students within and across the two classes.

\subsection{Performance on Uncued Assessments: Analyzing Student Behavior in the EcoMUVE}

How students behaved in the EcoMUVE offers a measure of what behavior looks like when students are not cued but rather are focused on exploring the virtual world. Of particular interest was where students across and within the contrast classes moved, whether to points local or distal to the pond, as they investigated the ecological puzzle following their discovery of the fish die-off. A map of the EcoMUVE environment was coded for proximity to the pond (See Figure 9.) and students' paths were assessed against this coded map. For the purposes of the analysis, the Spatially Distant and Action at a Distance categories were collapsed. (See Table 3.)

\section{[Insert Figure 9 about here.]}

The narratives and mapping of how each group investigated the EcoMUVE revealed a number of patterns in their explorations that corroborate the proximity data in Table 3. As each pair of students begins to explore the EcoMUVE, their movement is sporadic and appears unintentional. Without a focused problem to investigate, they tend to explore broadly and to spend time local and distal to the pond. (See Figure 10.) Most students went to the edges of the world and explored the extent of it suggesting that virtual worlds differ from real worlds given the ease of "seeing" the whole thing. They also explored the constraints of movement within the space. Amy and Uzuli spent time determining how they can travel and what the limitations are on their movement; for instance, whether or not they can go into the houses, whether or not they can jump, and if they can fall off the land into the water. The pairs find the various locations, including the edge of the MUVE, setting the boundaries within the environment. They seem to get familiar with their virtual surroundings within the first or second visit to the MUVE, noted by the pairs revisiting the same locations multiple times or by stating, "We've already been here." Two pairs find the "edge of the world" and the housing development in the first session. All of the pairs interact with animals, fish and humans beginning to use the field guides and camera functions. Within the first session, some students start to get a geographic sense of where things are. For example, Chloe said, "Go back to the pond, go back to Ranger Susan" and navigated back to that location directly from the housing development.

As the pairs learn about the fish die off, their movements become more constrained and more purposeful. They focus primarily on the pond (See Table 3. and Figures 11-12.) Once they know the exact date that the dead fish appear in the pond, they work before and after that date looking at the pond itself, taking population counts for 
the fish that are still alive and testing the water for different organisms and bacteria. They begin to develop strategies to seek out animals and humans in order to gather information and begin to discuss the data meaningfully, noticing trends in the increase or decrease of specific organisms. Towards the end of their time with EcoMUVE, the pairs spend more time looking at data and graphs than moving around the environment. However, the paths that they pursue begin to reach out towards more distant locations from the pond as fits with the hypotheses that they are investigating. (See Figures 11-12.) All of the students revealed a focusing of their explorations towards the hypotheses that they were considering and a willingness to move within the virtual world to locations that were local and distal to the pond. The patterns of exploratory movement reveal more similarities than differences between the classes, suggesting that there was not a discernible difference in the EcoMUVE based upon the experience of the augmented field trip.

\section{[Insert Figures 10-12 about here.]}

Testimony from others plays a powerful role in motivating students' explorations. Uzuli interacts with the virtual Non-Player Character (NPC), Maria Henriquez, who tells him, "The herons are eating the fish; I guess they're just picking up from where the raccoons left off last night." Uzuli then reports to the teacher that he thinks that "the raccoons might be the cause of the fishes' death." Another student reported that he was sure of his answer that sewage was the precipitating cause because he had heard it from a character in the EcoMUVE. When pushed for evidence to support his claim and his ability to evaluate the veracity of the statement, he argued that the character wouldn't be in the world if it wasn't true "because that's how assignments in school work." He was surprised to learn that this was not the case in EcoMUVE. Testimony from NPCs, Manny at the development and the golf course manager, was similarly compelling to students in leading them to explore hypotheses about fertilizer.

The pull of a more local potential source for the fertilizer is seen in two of the pairs. Both of the teams from the EcoMUVE/MBD Condition realized the possibility of a local cause for the fertilizer - that it came from the golf course. They explore this possibility for an extended period of time before moving on to the possibility of a more distant source. This is certainly a rational approach to problem-solving - to investigate local sources first before moving to more distant sources. Sean and Chloe focus on the golf course. On Day 3, they make an immediate assumption that sewage killed the fish. Sean says, "Yes, we know what caused it. The sewage..." On Day 4, Chloe says, "I don't think it was the sewage. I think it was the fertilizer." After further exploration, she says, "We figured it out." Sean fills in, "The day before it rained they were putting fertilizer on the golf course over here and on the instructions said not to put it on before it rains." Chloe adds, "So it washed away, into the pond and killed the fish."

On Day Six, Chloe is still grappling with the golf course as a source for the fertilizer. What is troubling to her is that she cannot figure out a mechanism for how it got into the pond. She says, "But the only problem with that is that how can it get... like how can it get from the golf course... like is there a drain it could go through? Is there any way that it could... cause it couldn't go uphill, down, into the drain, like... seep into the ground, go through, like I don't think that would happen."

Walker and Rose realize that fertilizer might have something to do with what happened to the fish and discuss the possibility, Walker says, "It could be the fertilizer. Maybe that's it." Rose remarks, "Someone dropped it in..." On Day 3, Walker says, "It just seems like it definitely happened." Rose adds, "But it only affected the big fish." On Day 4: She says, "It says not to do it before rain, and it got in the water...to prevent the loss of nutrients..." Walker adds, "Oh so maybe the water could have taken the nutrients out and it went into the plants and the fish ate them." "We know one person probably made a mistake with fertilizer." "Our theory is that the oxygenthere's not enough chlorophyll in the water and the plants died. The plants died because there was not enough sun."

However, they have difficulty isolating the source. They met the landscaper, Manny, putting fertilizer on the lawns at the more distal housing development on Day One and Day Two, yet they continue to revisit what they consider the misuse of the fertilizer by the caretaker at the golf course adjacent to the pond through Day Six until the point when they are asked by a teacher whether anyone else in the world has used fertilizer and then they rediscover Manny. Despite the earlier encounters, they did not make note of him or his fertilizer use at the time and didn't consider him important until many days into their inquiry.

Amy and Uzuli investigate the raccoons and other very local causes, such as the heron visiting the pond. After learning that herons do eat largemouth bass, they follow a heron around, watching to see whether it will cough up a dead fish. Eventually, they generate a very distant possible cause for the fish die-off-acid rain. They discover that on July $6^{\text {th }}$ it is raining and Amy remarks, "What if it's...something bad in the rain? ... And also, look at the water, its way lighter than it was." This discovery sparks a conversation about the effects of chemicals and global warming on water quality. Uzuli says, "The global warming goes into the clouds and when the clouds get heavy they mix with, like, bad chemicals to produce acid rain so it's bad for the animals." "I know," Amy responds, "but I still 
think the herons are eating the fish." Uzuli, thinking that acid rain may be playing a role, suggests that they test the $\mathrm{pH}$ level in the water. He gets the reading, which is 6.7, and states that the water is acidic. Amy calls out to the teacher, "So it must be chemicals!" Uzuli suggests that they test the water on the day that the fish died, but the class period ends before they have a chance to do so. They start the next session by taking a picture of a fox and noticing what it eats, but quickly shift to a discussion of $\mathrm{pH}$, Uzuli says, "Remember last time we found out about $\mathrm{pH}$ and maybe the acid in the water? So maybe it's the rain that's getting the acid in the water. So let's test out our theory." They move back and forth between different days, testing the $\mathrm{pH}$ level in the pond on each day. He comments, "I wonder what's getting the water all acidic. Let's go explore the village and see if there's any, like, cars.” Amy, who is still holding on to her theory about a predator; upon seeing turtles and squirrels, suggests that they find out their eating habits.

Amy and Uzuli also express sensitivity to noticing changes over time. Uzuli proposes that they "stay still in one place for a little bit, and examine" and that they "see how plants change on different days." They travel between different days for several minutes, looking at the pond. They explain to the teacher that the water quality has changed over different days, explaining that on certain days the water is green and/or foggy.

The fourth pair (MBD/EcoMUVE), Ted and Veronica, is somewhat more distracted than other pairs, seemingly by each other and sometimes spurred by information in the EcoMUVE. On Day 2, they spend time following a squirrel and traversing the golf course and then return to the pond, where they talk to Ranger Susan. They stumble upon a tool called "the atom tracker" and encounter a phosphorous atom, which is communicating from the squirrel's bloodstream. They then travel to the housing development and back via the pipe. When they get back to the pond, Ted comments about the pond water, "Why does it almost seem foggier?" They spend a few minutes traveling to the golf course, up into the hills, and then travel back to the pond without explanation. When they meet an NPC looking for her dog, they get lost in the prospect of finding the dog. They collect information that will eventually be useful to them, for instance, that the water is becoming greener and that on one day, it seems glassy on top. Even after Day 3 when the class has been discussed the Fish Die-Off, it does not appear to fully sink in until the end of session 4.

On Day 4, Ted suggests that they should focus their data collection on water and air measurements, and starts doing so for a number of organisms: bacteria, bluegills, bluegreen algae, green algae, herons, largemouth bass, and minnows. The teacher alerts them to the graphing function and they begin making graphs. Veronica suggests moving ahead on the calendar, but Ted moves them back to July 10th so he can "test all the water stuff" and gather data that they missed. They notice covariation patterns and discuss them. Ted reports, "The water temperature is slowly rising but the dissolved oxygen dropped suddenly on July 22nd. The phosphates are now up a little bit, and the nitrates are down after climbing, or after a sudden spike and then a decline so it's now declining. And the turbidity spiked on July 16th and now went back to a little around the normal, or we can't really know for normal, what normal is and so..." Ted also notes from the graphs that the three fish populations are all slowly decreasing. They "skip ahead," and end up on the day of the fish die-off finally realizing what the population charts had been suggesting. Veronica exclaims, "Look at all the dead fish!" They viewed the bluegill data to confirm that there are zero in the population. They continue systematically gathering data to fill the chart including water quality measurements. At the end of class, they navigate to the golf course without explaining why and encounter an NPC talking about the new housing development. Around this time, they hear a classmate discussing a hypothesis about the relationship between water temperature, the dissolved oxygen, and the fish. This leads Ted and Veronica to do a learning quest about dissolved oxygen. Eventually, they do construct an explanation of what happened to the fish based primarily on the information about phosphates from the data charts and realize the connection in the covariation patterns to the heavy rains in early July; thus, they look for and find the water pipe that leads them to the development.

This behavioral information suggests that all of the teams eventually manage to pursue distal causes for the fish die-off, however, their means of getting there differ. The two EcoMUVE/MBD teams thoroughly investigate the more local golf course - continuing to pursue it as a source for phosphates before eventually ruling it out and considering an even more distant account. By contrast, neither MBD/EcoMUVE team so fully investigated a local cause, but they do not appear to be as systematic in their discoveries and so the golf course never fully registers as a possible near source of phosphates. One team, Amy and Uzuli, oscillates between very visual and local causes such as predators, and distant, non-obvious causes such as acid rain. The second pair finds their way using covariation and mechanism data. At no point in either set of transcripts do these students mention their experience at the pond for EcoMOBILE or discuss its relevance to the puzzle that they are trying to solve.

3.2 Performance on Uncued Assessments: Analyzing Student Behavior in the EcoMOBILE Experience at the Pond 
This section of the results reports on the responses of 20 students in the ten pairs balanced by class. In this data, if the students transferred learning from EcoMUVE to the MBD components, we would expect to see evidence of that in the EcoMUVE/MBD group in the initial observations that they made at the pond prior to experiencing the EcoMOBILE instructional components particularly in comparison to the MBD/EcoMUVE group.

Examining the classes as reference populations for one another is most informative in considering the initial observations that students make at the pond. The focus of the EcoMUVE/MBD group is in stark contrast with the students who had not completed EcoMUVE first. (See Tables 4 and 5.) They all appear to have transferred some aspects of their EcoMUVE experience. Their comments address what is around the pond whether streams, cars, or possible sewage pipes. We see references to spatial proximity and distance as variables to be considered, mention of non-obvious potential causes, particularly those in the EcoMUVE such as dissolved oxygen, phosphates, and nitrates. In contrast, the pairs who experienced EcoMUVE following the MBD also make many observations, but they are more likely to talk about the flora and fauna that they can see around them and the behaviors of particular animals. For instance, Amy and Uzuli focus on what is in the water. They are very observant and notice a frog that is well camouflaged on the bottom of the pond. Interestingly, neither group talks about change over time in their initial observations at the pond. It is possible that, because the EcoMUVE scenario plays out over six weeks in the summer, the importance of attending to change over time was less salient than other aspects of the experience.

[Insert Tables 4 and 5 about here.]

After participating in the EcoMobile Instructional Components, all of the students incorporated this information into their open-ended observations afterwards. Many of the students talk about the history of the pond and consider how they were surprised to learn how much change there has been over time. Change over time is mentioned repeatedly in the post-EcoMOBILE observations. Across the two groups, the group that had not finished EcoMUVE made the greatest gains in post-EcoMOBILE observations. They considered how the water is connected to other places and how there might be things in the water that they had not previously imagined. (See Table 5.)

\section{Discussion}

In sum, this work suggests that both groups of students made subtle shifts towards more expert notions of ecosystems that include recognition of change over time, realizing the potential of distant drivers of change in addition to local ones, and learning about particular nonobvious variables that are essential parts of the causal mechanisms at play in ecosystem dynamics. Students' exploration within the EcoMUVE became more focused and hypothesis-driven as they collected more information and refined their ideas about what might be happening. Some of these hypotheses led them further from the pond and they shifted their efforts to focus there. Their explanations suggest deep exploration and learning of the causal story of the ecosystem.

Further, there was clear evidence that the students who experienced the full EcoMUVE curriculum prior to their pond visit transferred aspects of this experience to their initial observations at the real pond. This was most exciting because it was apparent in how they focused their attention, the questions that they asked, and the information that they pursued. They brought framing about spatial proximity, temporal change, and non-obvious variables to open-ended questions that did not specifically ask them to reason about any one aspect of the pond. The study considered forms of near transfer with aligned surface features between the real and virtual worlds. Presumably the aligned surface features helped to cue the possibility for transfer.

The evidence for transfer in the other direction from EcoMOBILE to EcoMUVE was less compelling. It is possible that the initial learning was not deep enough to enable students to extract it and apply it back to the EcoMUVE environment. The dosage of the EcoMOBILE experience was certainly much less in the 1.5 hour field trip than in the two-week EcoMUVE experience. It is also possible that the effects were too subtle to detect. Recall that both of the teams who completed all of EcoMUVE and then experienced EcoMOBILE focused on the fertilizer on the adjacent golf course in EcoMUVE as an initial cause of the Fish Die-off and persisted with this hypothesis for a number of days. None of the students in the MBD/EcoMUVE condition did so. The analysis of the EcoMUVE paths was a small in-depth study that closely analyzed many hours of video and the accompanying audio and log-file data. It offers interesting questions and possible paths for further inquiry with less time intensive methodologies.

It is also promising to see how much students learned while on their pond trip by transporting the learning to contexts typically targeted for transfer. This outcome argues for the efficacy of "turning transfer inside out." While this doesn't negate the need for transfer to new contexts, in this case, new ecosystems, it ensures that learning applies to at least one context that matters beyond the walls of school. 
This small, intensive examination of students' learning suggests promise for the roles of virtual worlds and MBDs in helping students to learn and to transfer complex ecosystems concepts. It is particularly noteworthy that students were learning concepts that involve forms of causal complexity that typically do not fit their default assumptions and that they translated this learning to what they focused on as they investigated at the pond. The challenges of teaching about dynamic systems (e.g. Hmelo-Silver and Azevedo 2006) and teaching for transfer (Day and Goldstone 2012) are well documented and considered some of the most intractable in the cognitive science literature. To see a shift towards noticing the extended spatial surroundings, non-obvious variables, and thinking about change over time while at the pond, as evidenced in their uncued, open-ended observations, is definitely a very promising step forward.

\section{Acknowledgements}

We would like to express our appreciation to the teachers and students who contributed their time to this project and enabled us to collect data on their reasoning patterns. Thank you to Maya Bialik, Amber K. Boyd, Maleka Gramling, Couger Jimenez Jaramillo, Tim Johnson, Miles Malbrough, Daniel Oh, and S. Lynneth Solis for their assistance in data collection, transcribing, and analysis. Thank you to Daniel Hackett, Brandon Pousley, and the Cambridge Water Department for their assistance in developing components for EcoMOBILE.

This work is supported by National Science Foundation, Grant No. DRK12 1118530 to Chris Dede and Tina Grotzer. All opinions, findings, conclusions or recommendations expressed here are those of the authors and do not necessarily reflect the views of the National Science Foundation. EcoMUVE was supported by the Institute of Education Sciences, U.S. Department of Education, Grant No. R305A080514 to Chris Dede and Tina Grotzer. All opinions, findings, conclusions or recommendations expressed here are those of the authors and do not necessarily reflect the views of the Institute for Education Sciences.

\section{References}

Atran, S. (1995). Causal constraints on categories and categorical constraints on biological reasoning across cultures. In D. Sperber, D. Premack, \& A.J. Premack (Eds.), Causal cognition: A multidisciplinary debate (pp. 205-233). Oxford: Clarendon Press.

Barab, S. \& Squire, K. (2004). Design-based Research: Putting a stake in the ground. The Journal of the Learning Sciences, 13(1), 1-14.

Chi, M.T.H., \& Van Lehn, K. (2012) Seeing deep structure from the interactions of surface features. Educational Psychologist, 47(3), 177-188.

Danish, J.A., Peppler, K., Phelps, D., \& Washington, D. (2011). Life in the hive: Supporting inquiry into complexity within the Zone of Proximal Development. Journal of Science Education and Technology, 20(5), 454-467.

Day, S.B. \& Goldstone, R.L. (2012). The import of knowledge export: Connecting findings and theories of transfer of learning, Educational Psychologist, 47(3), 153-176.

Dede C. (2009). Immersive interfaces for engagement and learning. Science, 323(5910): 66-69.

Goldstone, R.L. \& Sakamoto, Y. (2003). The transfer of abstract principles governing complex adaptive systems, Cognitive Psychology 46, 414-466.

Gopnik, A. \& Glymour, C. (2002). Causal maps and Bayes nets: A cognitive and computational account of theory formation. In P. Carruthers, S. Stich, \& M. Siegal (Eds.). The Cognitive Basis of Science. (pp. 117-132) NY: Cambridge University Press.

Gopnik, A. \& Schulz, L. (2007). Introduction. In A. Gopnik and L. Schulz (Eds.) Causal learning, Oxford Press.

Grotzer, T.A., \& Basca, B.B. (2003). How does grasping the underlying causal structures of ecosystems impact students' understanding? Journal of Biological Education, 38(1) 16-29.

Grotzer, T.A., Kamarainen, A., Tutwiler, M.S, Metcalf, S, \& Dede, C. (2013). Learning to reason about ecosystems dynamics over time: The challenges of an event-based causal focus. BioScience, 63(4), 288-296.

Grotzer, T.A. \& Tutwiler, M.S. (2014). Simplifying causal complexity: How interactions between modes of causal induction and information availability lead to heuristic driven reasoning. Mind, Brain, and Education, 8(3), 97114.

Harp, S.F. \& Mayer, R.E. (1998). How seductive details do their damage: A theory of cognitive interest in science learning. Journal of Educational Psychology, 90, 414-434. 
Harris, P.L. (2002). What do children learn from testimony? In P. Carruthers, S. Stich, \& M. Siegal (Eds.). The cognitive basis of science (pp. 316-334), New York: Cambridge University Press.

Hmelo-Silver, C.E. \& Azevedo, R. (2006). Understanding complex systems: Some core challenges The Journal of the Learning Sciences 15 (1), 53-61

Hmelo-Silver, C. E. \& Pfeffer, M. G. (2004). Comparing expert and novice understanding of a complex system from the perspective of structures, behaviors, and functions. Cognitive Science, 28. 127-138.

Hmelo-Silver, C. E., Marathe, S., \& Liu, L. (2007). Fish swim, rocks sit, and lungs breathe: Expert-novice understanding of complex systems. Journal of the Learning Sciences, 16, 307-331.

Hogan, K., \& Fisherkeller, J. (1996). Representing students' thinking about nutrient cycling in ecosystems: Bidimensional coding of a complex topic. Journal of Research in Science Teaching, 33(9), 941-970.

Jacobson, M. J. (2001). Problem-solving, cognition, and complex systems: Differences between experts and novices. Complexity 6(3), 41-49.

Keil, F.C. (1994). The birth and nurturance of concepts by domains. In L. Hirschfield \& S. Gelman (Eds.), Domain specificity in cognition and culture (pp. 234-254). NY: Cambridge University Press.

Klopfer, E. \& Yoon, S. (2005). Using Palm Technology in Participatory Simulations of Complex Systems: A New Take on Ubiquitous and Accessible Mobile Computing. Journal of Science Education and Technology. 14(3), 287-295.

Metcalf, S.J., Kamarainen, A., Tutwiler, M.S., Grotzer, T.A. \& Dede, C. J. (2011). Ecosystem science learning via multi-user virtual environments. International Journal of Gaming and Computer-Mediated Simulations. 3(1)8690.

Penner, D. (2000). Explaining systems: Investigating middle school students' understanding of emergent phenomena. Journal of Research in Science Teaching, 37(8), 784-806.

Perkins, D.N., Jay, E., \& Tishman, S. (1993). Beyond abilities: A dispositional theory of thinking. The MerrillPalmer Quarterly, 39, 1-21.

Perkins, D.N., \& Salomon, G. (2012). Knowledge to go: A motivational and dispositional view of transfer. Educational Psychologist, 47(3), 248-258.

Raia, F., (2008). Causality in complex dynamic systems: A challenge in earth systems science education. Journal of Geoscience Education, 56(1) 81-94.

Ratterman, M. J., \& Gentner, D. (1998). The effect of language on similarity: The use of relational labels improves young children's performance in a mapping task. In K. Holyoak, D. Gentner, \& B. Kokinov (Eds.), Advances in analogy research: Integration of theory and data from the cognitive, computational, and neural sciences (pp. 274-282). Sophia: New Bulgarian University.

Shepardson, D.P., Wee, B., Priddy, M., Schellenberger, L., Harbor J. (2007). What is a watershed?: Implications of student conceptions for environmental science education and the National Science Education Standards. Science Education, 91, 544-578.

Tal, T., Alon, N.L., \& Morag, O. (2014). Exemplary practices in field trips to natural environments. Journal of Research in Science Teaching, 51, 430-461.

Weathers, K., Strayer, D. \& Likens, G. (2013). Fundamentals of Ecosystem Science. Waltham, MA: Academic Press. 
Table and Figure Captions:

Figure 1. Points of Instructional Challenge in Transfer of Learning

Figure 2. Image of Information Available Through EcoMOBILE Virtual Binoculars

Figure 3. Image of EcoMOBILE Time Traveler

Figure 4. Pre- to Post- Shifts in Percentages of Response Type on the Ecosystems Causal Dynamics Assessment

Figure 5. Pretest Spatial Response Types Across and Within Classes on the ADCT Assessment

Figure 6. Post-Test Spatial Response Types Across and Within Classes on the ADCT Assessment

Figure 7. Pretest Temporal Response Types Across and Within Classes on the ADCT Assessment

Figure 8. Post-test Temporal Response Types Across and Within Classes on the ADCT Assessment

Figure 9. Mapping of Proximity Locations within EcoMUVE for Coding

Figure 10. EcoMUVE Day One Random Exploration: Sean and Chloe

Figure 11. EcoMUVE Movement Patterns Across Multiple Days: Uzuli and Abby

Figure 12. EcoMUVE Movement Patterns Across Multiple Days: Walker and Rose

Table I: Sequence of Intervention Components for Each Class

Table II. Types of Possible Causes Identified from Pre to Post-test on the Ecosystems Causal Dynamics Assessment

Table III. Major Movements within the EcoMUVE Spatial Locations

Table IV. Observations by Class of Spatial/Temporal Relationships and Non-Obvious Variables at the Pond

Table V. Comparison of EcoMOBILE Observations by Reference Population 


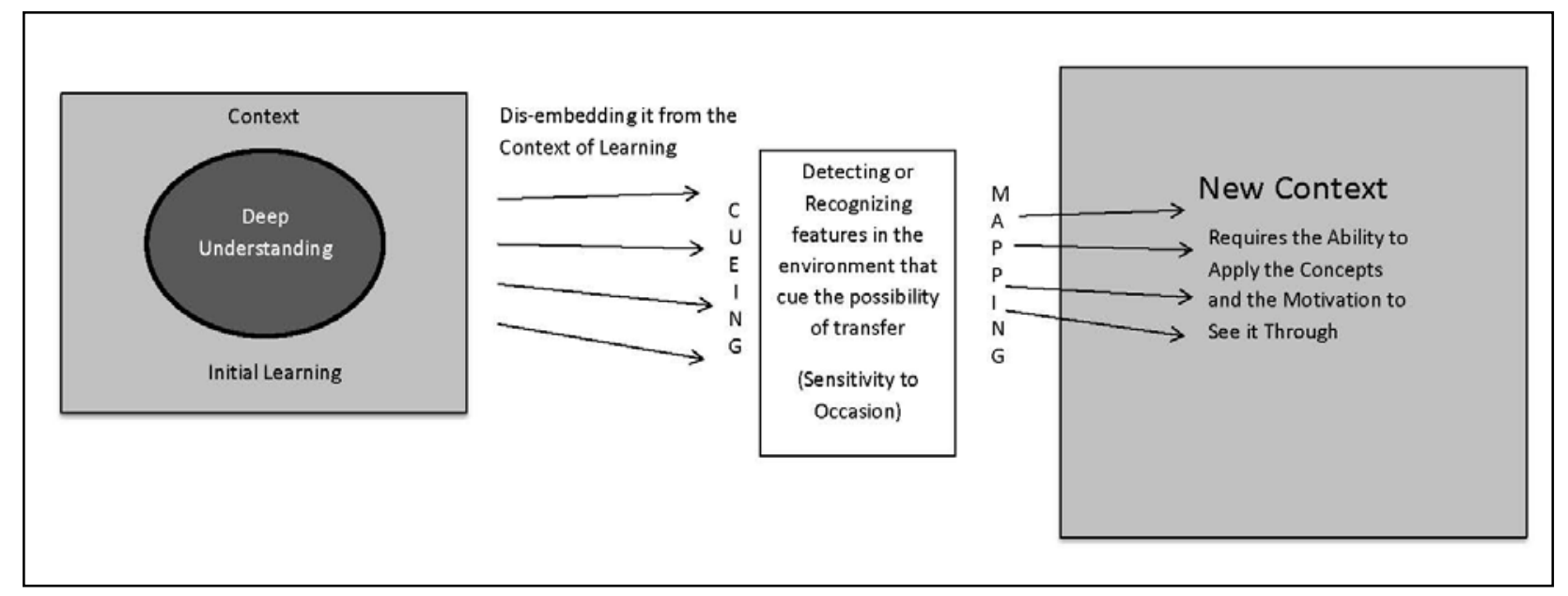

Figure 1. Points of Instructional Challenge in Transfer of Learning

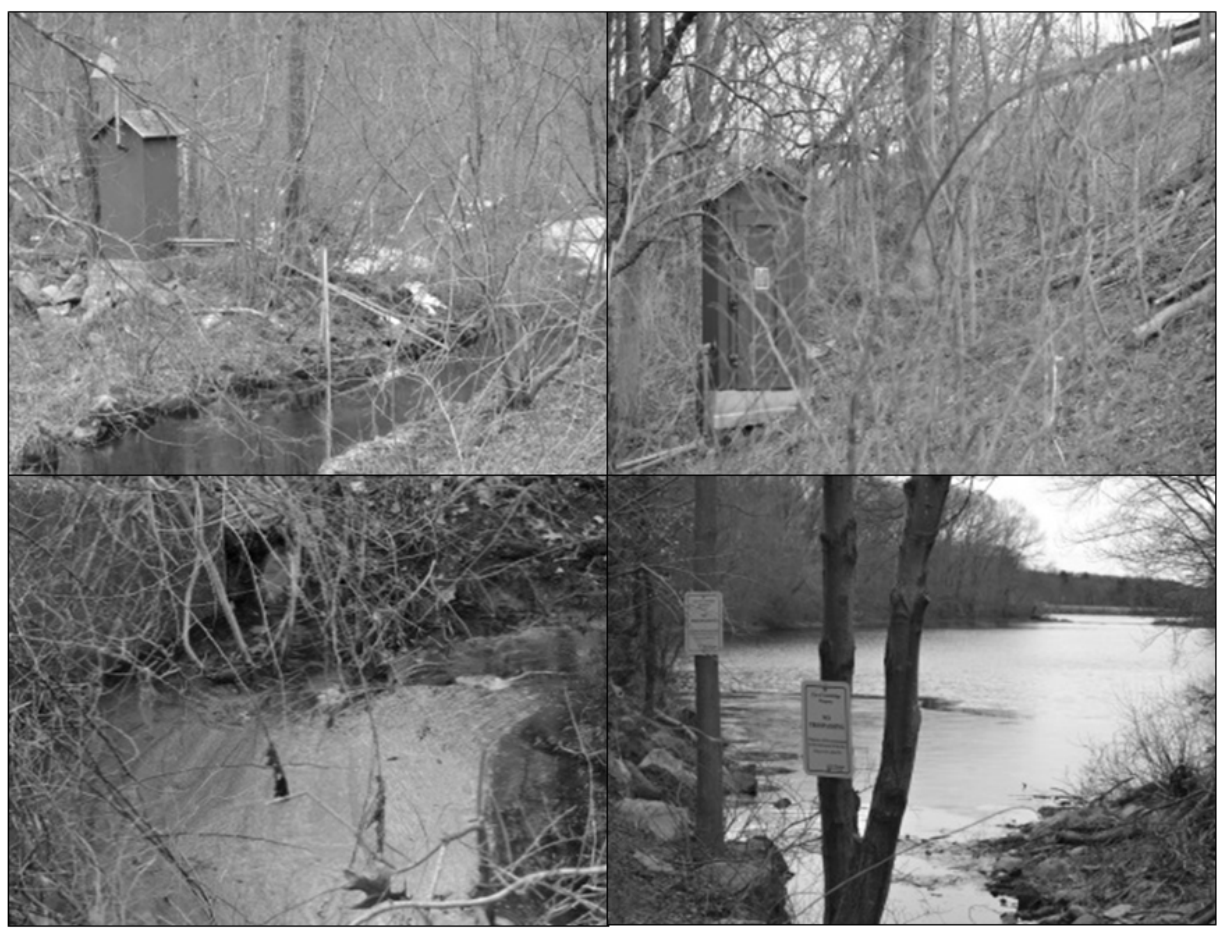

Figure 2. Image of Information Available Through EcoMOBILE Virtual Binoculars 


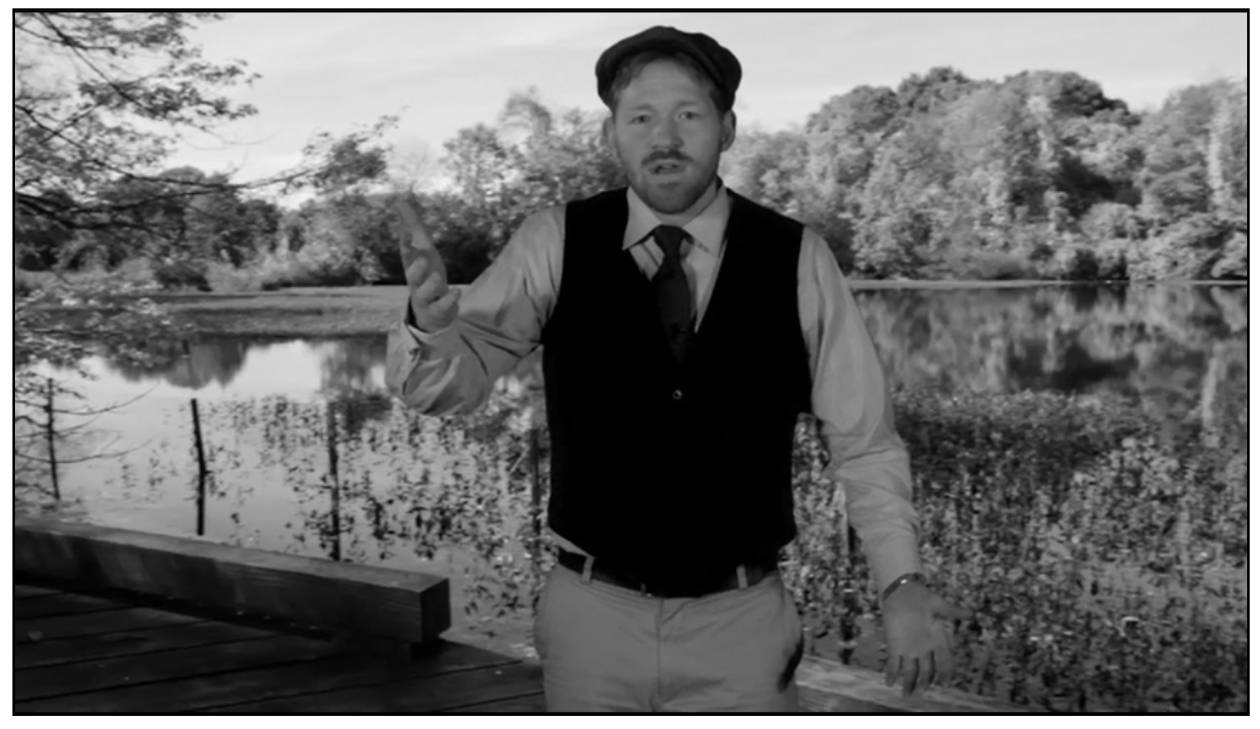

Figure 3. Image of ECoMOBILE Time Traveler

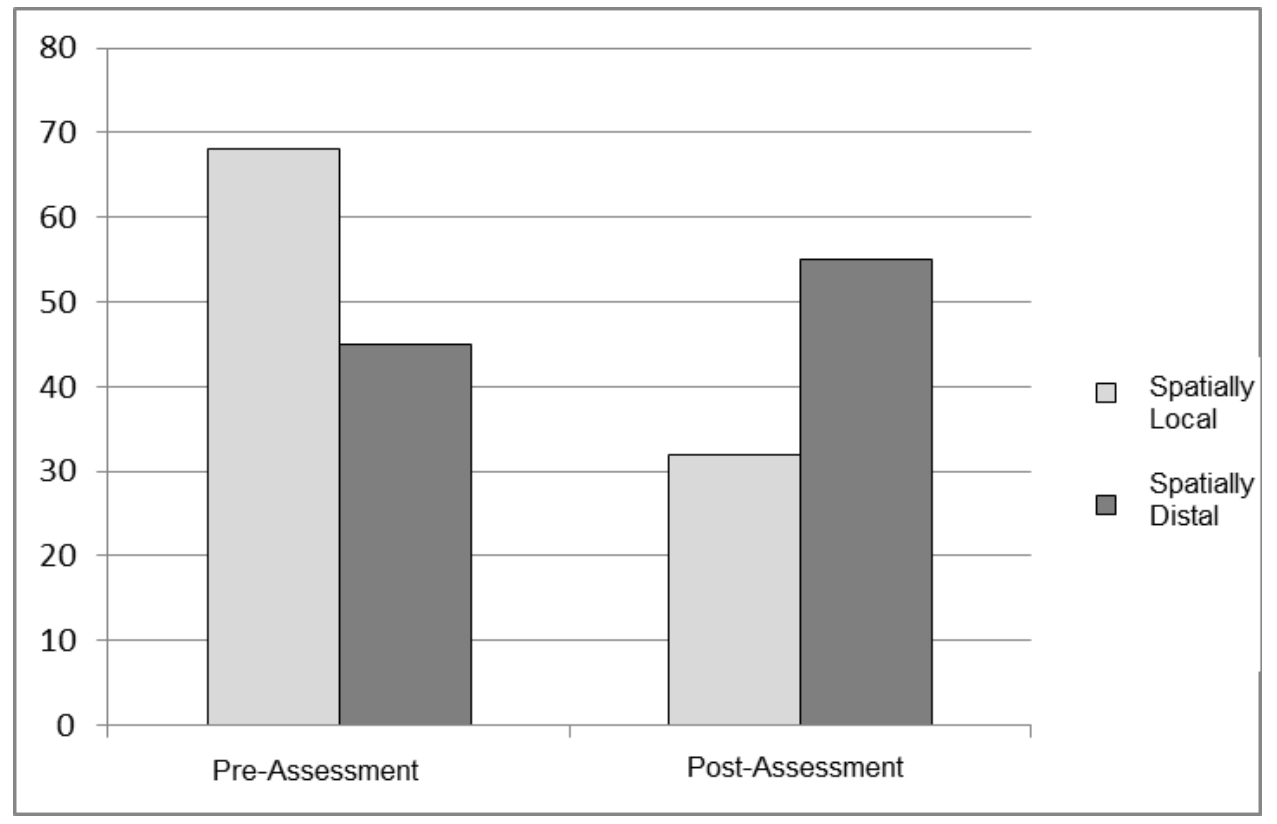

Figure 4. Pre- to Post- Shifts in Percentages of Response Type on the Ecosystems Causal Dynamics Assessment 


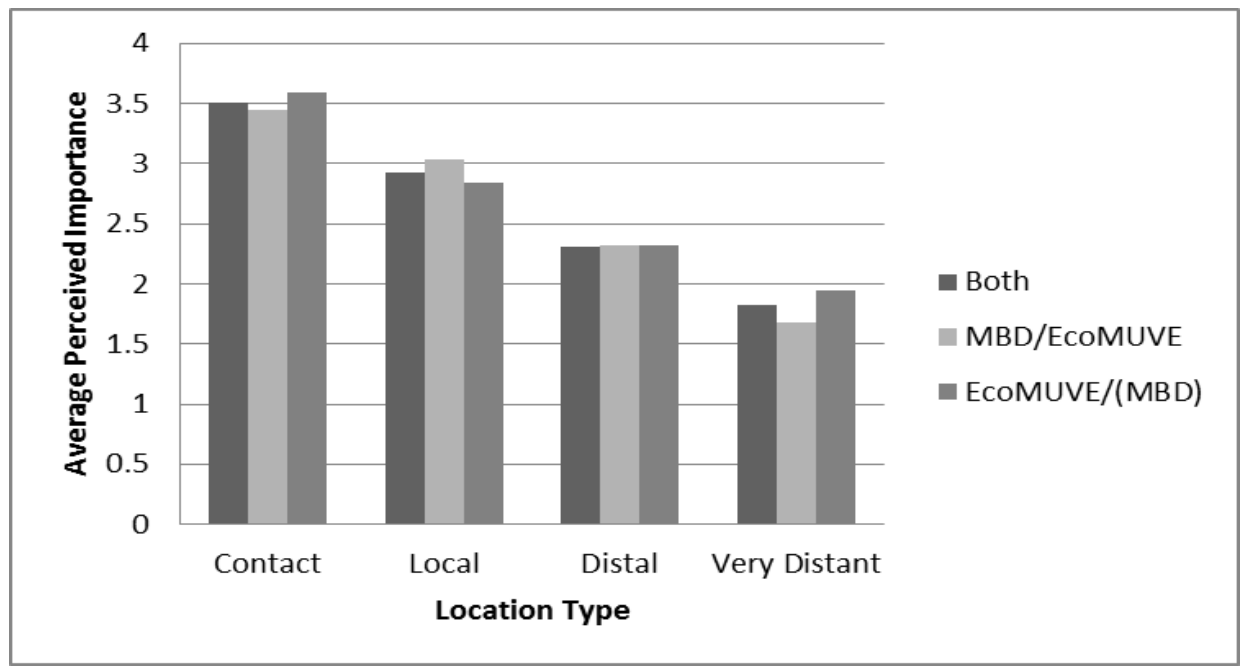

Figure 5. Pretest Spatial Response Types Across and Within Classes on the ADCT Assessment

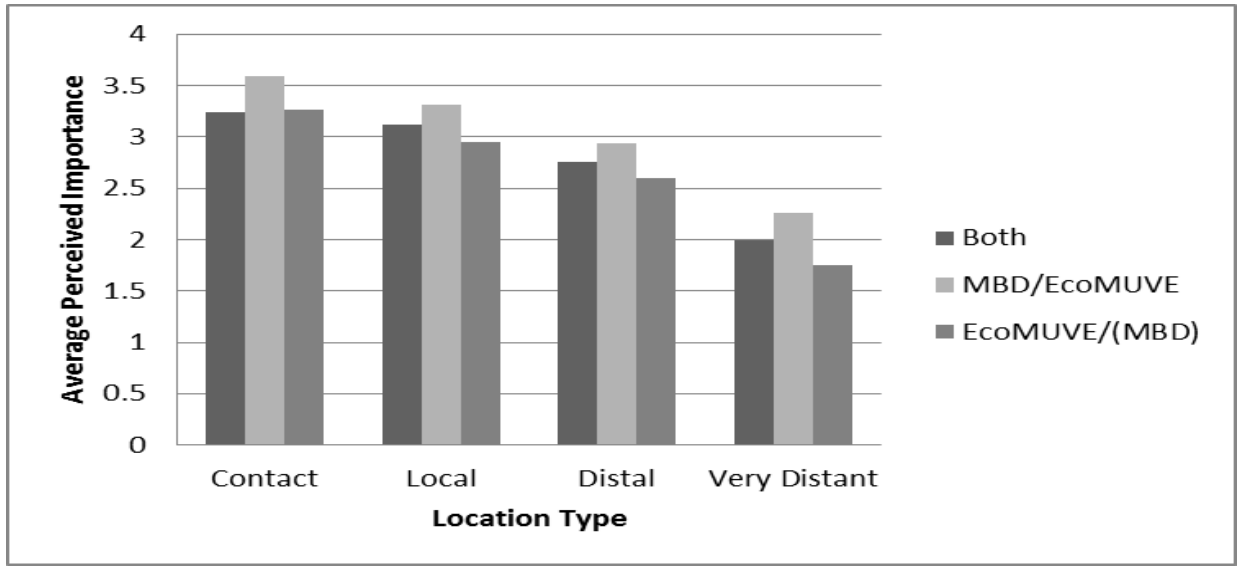

Figure 6. Post-Test Spatial Response Types Across and Within Classes on the ADCT Assessment

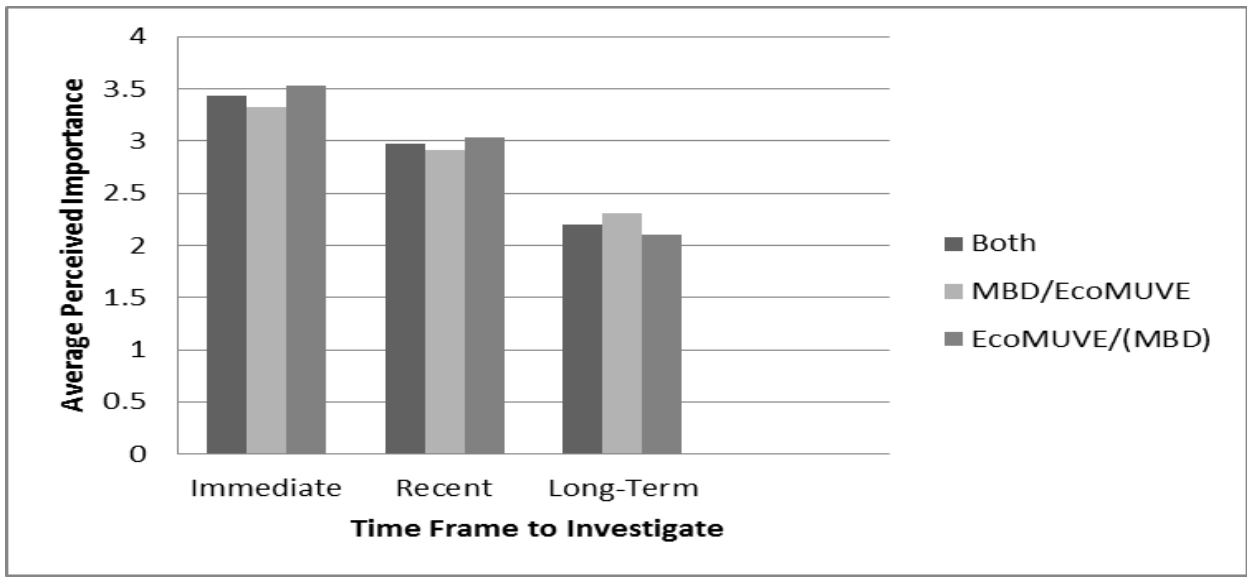

Figure 7. Pretest Temporal Response Types Across and Within Classes on the ADCT Assessment 


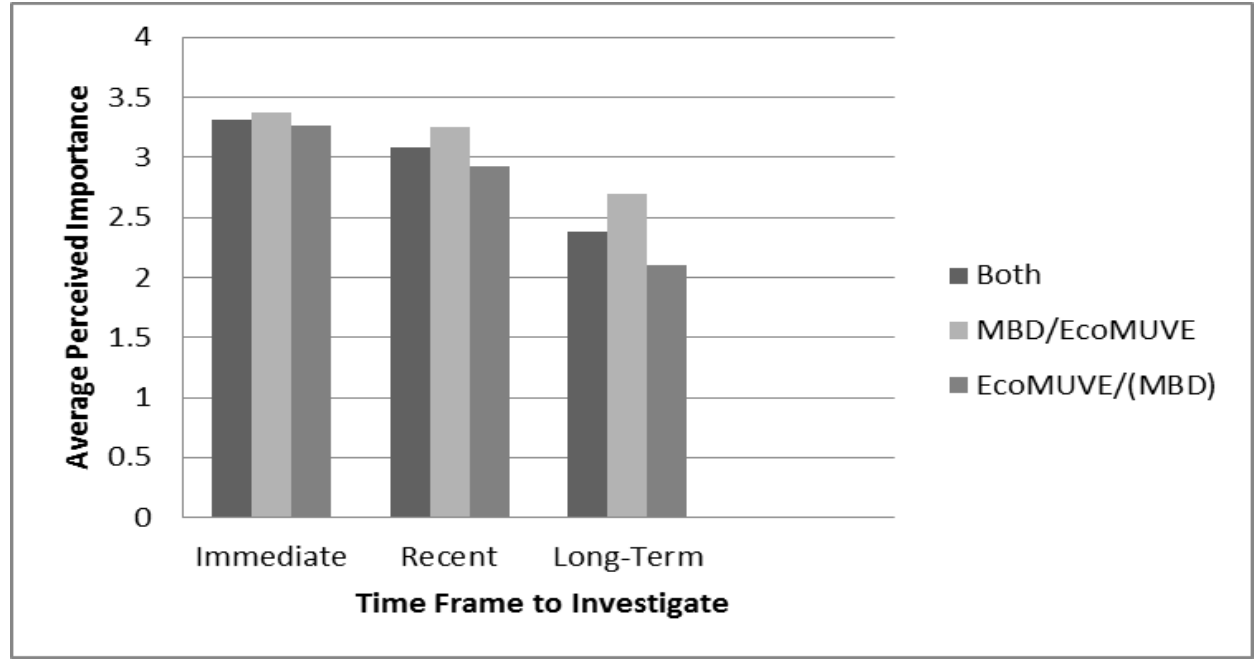

Figure 8. Post-test Temporal Response Types Across and Within Classes on the ADCT Assessment

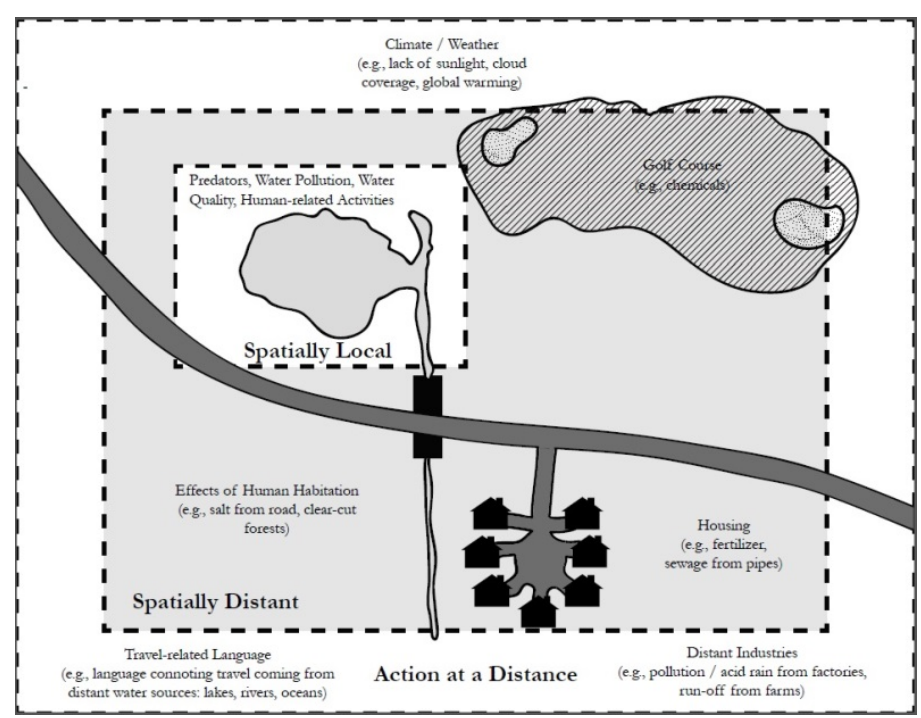

Figure 9. Mapping of Proximity Locations within EcoMUVE for Coding 


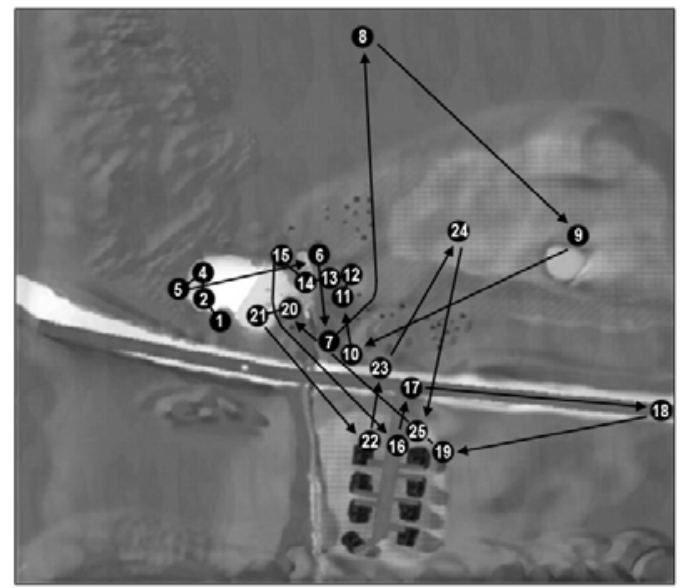

Figure 10. EcoMUVE Day One Random Exploration: Sean and Chloe

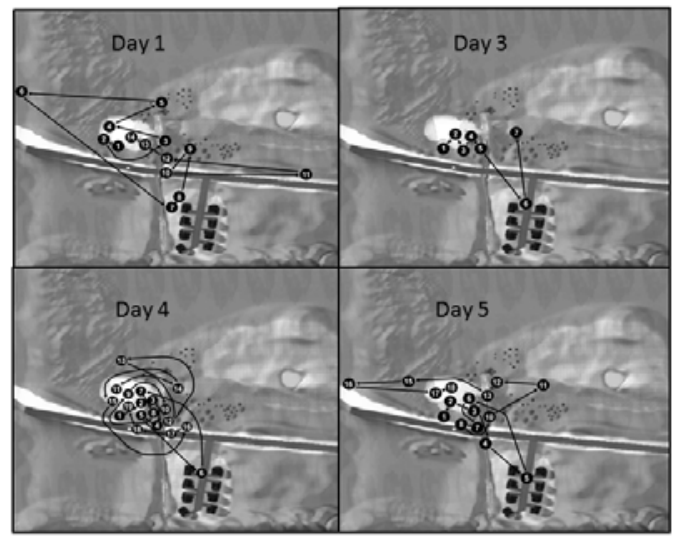

Figure 11. EcoMUVE Movement Patterns Across Multiple Days: Uzuli and Abby 


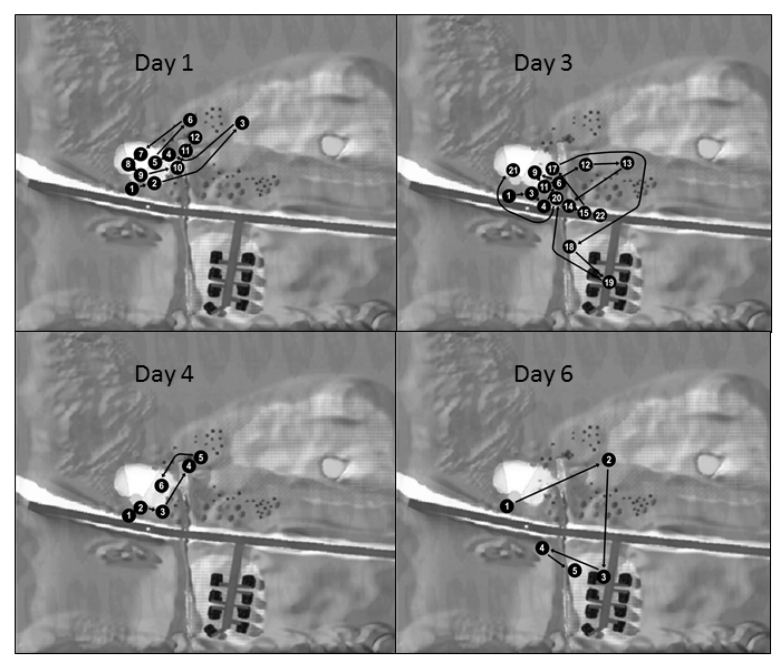

Figure 12. EcoMUVE Movement Patterns Across Multiple Days: Walker and Rose 
Table I.

\begin{tabular}{|l|l|l|}
\hline & EcoMUVE/MBD Class & MBD/EcoMUVE Class \\
\hline 1 & ADCT and ECDA & ADCT and ECDA \\
\hline 2 & EcoMUVE & EcoMOBILE (Embedded Pre-Post Assessment) \\
\hline 3 & ADCT and ECDA & EcoMUVE \\
\hline 4 & EcoMOBILE (Embedded Pre-Post Assessment) & ADCT and ECDA \\
\hline
\end{tabular}

Table II.

\begin{tabular}{|c|c|c|}
\hline \multicolumn{3}{|c|}{ Ecosystems Causal Dynamics Assessment } \\
\hline Across Classes $(n=39)$ & Spatially Local & Spatially Distal \\
\hline Pre-Assessment & $68 \%(\underline{\mathrm{M}}=1.95, \underline{\mathrm{S}}=.80)$ & $32 \%(\underline{\mathrm{M}}=0.95, \underline{\mathrm{S}}=.69) * *$ \\
\hline Post-Assessment & $45 \%(\underline{M}=0.73, \underline{S D}=.98)$ & $55 \% \quad(\underline{M}=0.89, \underline{S D}=.76) n s$ \\
\hline
\end{tabular}

${ }^{* *} \mathrm{p}<.0001$

Table III.

\begin{tabular}{|c|c|c|c|c|c|c|c|c|c|c|c|c|}
\hline \multirow[t]{2}{*}{ Condition } & \multicolumn{2}{|l|}{ Day 1} & \multicolumn{2}{|l|}{ Day 2} & \multicolumn{2}{|l|}{ Day 3} & \multicolumn{2}{|l|}{ Day 4} & \multicolumn{2}{|l|}{ Day 5} & \multicolumn{2}{|l|}{ Day 6} \\
\hline & Local & Distal & Local & Distal & Local & Distal & Local & Distal & Local & Distal & Local & Distal \\
\hline \multicolumn{13}{|l|}{ MBD/EcoMUVE } \\
\hline Ted and Veronica & 8 & 1 & 18 & 8 & 12 & 6 & $21 * *$ & 2 & 12 & 0 & 1 & 0 \\
\hline Amy and Uzuli & 8 & 6 & 10 & 5 & 5 & 2 & $18^{*}$ & 1 & 14 & 4 & 2 & 1 \\
\hline \multicolumn{13}{|l|}{ EcoMUVE/MBD } \\
\hline Chloe and Sean & 13 & 2 & 18 & 9 & 6 & 11 & $10^{*}$ & 6 & 2 & 2 & 10 & 2 \\
\hline Walker and Rose & 10 & 2 & 16 & 7 & 16 & 6 & $6^{*}$ & 0 & 2 & 0 & 1 & 4 \\
\hline
\end{tabular}

*First Day of Exploration Following Discovery of Fish Die-Off

**They are told of the fish die-off at the end of Day 3, but it sinks in completely towards the end of Session 4.

Table IX.

\begin{tabular}{|l|l|l|l|l|l|l|l|}
\hline Condition & \multicolumn{2}{|l|}{ Pre-observations at the Pond } & & \multicolumn{2}{l|}{ Post-observations at the Pond } \\
\hline $\begin{array}{l}\text { MBD/ } \\
\text { EcoMUVE } \\
\text { (MBD Only) }\end{array}$ & Spatial & Temporal & $\begin{array}{l}\text { Non- } \\
\text { obvious }\end{array}$ & & Spatial & Temporal & $\begin{array}{l}\text { Non- } \\
\text { Obvious }\end{array}$ \\
\hline Ted and Veronica & 1 & 0 & 2 & & 2 & 4 & 2 \\
\hline Uzuli and Amy & 1 & 0 & 2 & EcoMOBILE & 2 & 0 & 2 \\
\hline Ely and Anna & 0 & 0 & 0 & & 1 & 9 & 0 \\
\hline Christa and Fred & 0 & 0 & 0 & Instructional & 1 & 12 & 0 \\
\hline Timmy and Ilyan & 3 & 0 & 1 & & 4 & 3 & 3 \\
\hline $\begin{array}{l}\text { EcoMUVE/ } \\
\text { MBD (Both) }\end{array}$ & & & & Components & & & \\
\hline Sean and Chloe & 2 & 0 & 9 & & 2 & 6 & 2 \\
\hline Walker and Rose & 1 & 0 & 2 & & 0 & 1 & 0 \\
\hline Alec and Ned & 2 & 0 & 9 & & 1 & 4 & 3 \\
\hline Ramesh and Pearl & 5 & 0 & 6 & & 2 & skipped & 2 \\
\hline Evan and Oliver & 2 & 0 & 1 & & 0 & 5 & 0 \\
\hline
\end{tabular}




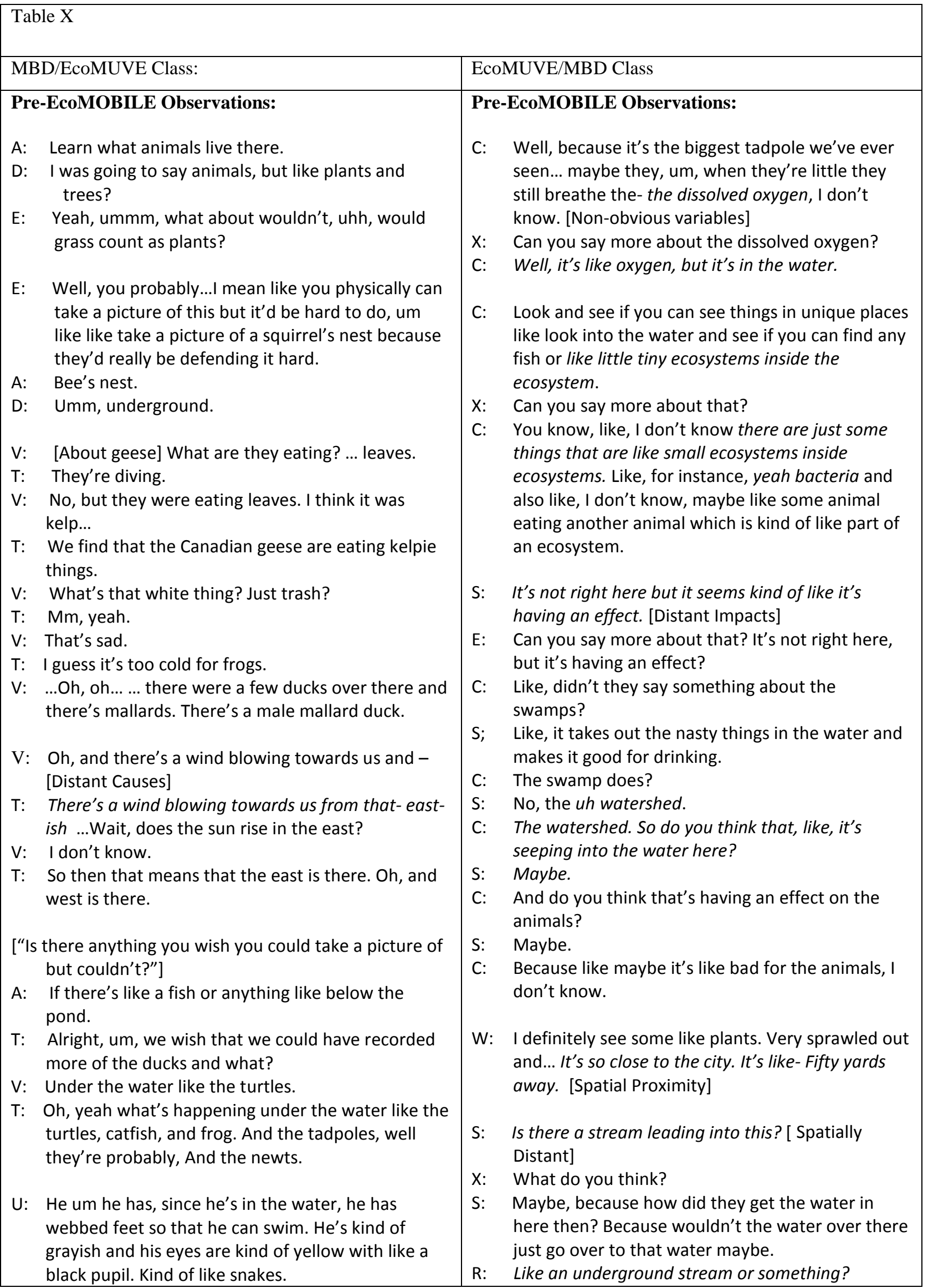


$\mathrm{X}$ : ...Can you think of any reasons why it might be nice for him to stay very still?

$\mathrm{U}$ : So that we can't see him, and then he can camouflage.

A: Maybe he's like, maybe the water's a little colder, and so sometimes if you like if you go like this, and if you kind of go like that (covers face with jacket), you stay a little warm.

A: So we found a frog at Black's Nook, so we have seen nine ducks and females and males.
S: There might be, but isn't there water over there on the other side of the larger fence?

[Things that are hard to see...]

S: Underground.

R: Bacteria [Non-Obvious]

$\mathrm{S}: \quad$ Sure. Underground things I guess.

$\mathrm{X}$ : Bacteria? Are there bacteria in the pond?

$\mathrm{S}: \quad$ Yes. We learned that in EcoMUVE.

$\mathrm{X}$ : Learned what?

S: There's bacteria in the pond.

$\mathrm{X}$ : Could you see it?

R: Yeah.

S: Nope! I don't know.

$\mathrm{X}$ : You could see the bacteria in the pond?

$\mathrm{R}$ : In the submarine.

$\mathrm{N}$ : Anyways...anyways, so there were probably a lot of, um, diverse amount of, uh, water wildlife.

A: You should probably also make sure that there isn't, um, like landfill or waste or sewage going into it. [Distant Impacts]

$\mathrm{N}$ : Or some sort of, um, toxins...[Non-Obvious]

A: But I also notice that there's like a golf flag over there or something.

$\mathrm{N}$ : Yeah, that's the golf course. [Spatial Proximity]

A: Well, I hear some trucks and cars moving over there.

$\mathrm{N}$ : Yeah, I also heard a lot of birds.

A: Um, sure I guess, but I would have said, um, explore the surrounding to see what kind of climate it is.

$\mathrm{N}$ : Um, so yeah, explore the surrounding area, get, um...get various things to let the animals survive like trees and things... [Spatial Surroundings]

A: The-the water isn't very murky, it's very, very clear, so you can see all the way-you can see the bottom of it very clearly.

$\mathrm{N}$ : So it has a low turbidity.

A: Very low turbidity. Yeah.

$\mathrm{N}$ : Well, I knew there were these plants over here, but I didn't know how they grew, and that's something I'm trying to know. How they grow, and what they do when they grow. It's like what's their job in this ecosystem?

A: So that's something you want to learn, how they grow, or what's their supplement?

$\mathrm{N}$ : Like food, or they create oxygen for fish? I don't know. Dissolved oxygen and stuff.

A: What's something you already knew, and you 


\begin{tabular}{|c|c|}
\hline & $\begin{array}{l}\text { notice a lot today? } \\
\mathrm{N}: \quad \text { I noticed there's um, well, I noticed that there was } \\
\text { low turbidity in the water. } \\
\mathrm{A}: \quad \text { Mm yeah, I probably wouldn't have thought there } \\
\text { was, uh, low turbidity. } \\
\mathrm{N}: \quad \text { Yeah, I would have been higher turbidity given that, } \\
\text { there might be... [Speaks in terms of levels--higher } \\
\text { and lower] } \\
\mathrm{A}: \quad \text { And for those of you who don't know what } \\
\text { turbidity means, turbidity is like how cloudy the } \\
\text { water is from particles. } \\
\mathrm{N}: \quad \text { And stuff. }\end{array}$ \\
\hline $\begin{array}{l}\text { Post-EcoMOBILE Observations: } \\
\text { F: It made me think about it like uh, is that things } \\
\text { really change fast and that um things will change } \\
\text { faster than we realize but from um an EcoMobile } \\
\text { we can actually see and tell people, ask people } \\
\text { from the past what they saw when they were our } \\
\text { age, and now we can, we know what happened } \\
\text { back in the day and now we know a lot more than } \\
\text { we did before without EcoMobile. [Change over } \\
\text { time] } \\
\text { C: because it sounds like before it was way more } \\
\text { dirtier. People were trying to like drowned it and } \\
\text { everything. And, now it looks so pretty and you } \\
\text { can't even tell that anybody tried to do that } \\
\text { because all the cars and everything they threw in } \\
\text { probably dissolved or made dirt... } \\
\text { C: Umm, I would say that I think you should use the } \\
\text { teletransporter because you see people in the past } \\
\text { and they look and then they tell you what Black } \\
\text { Nook looked like before and you can kind of } \\
\text { picture it differently. It kind of changes the way } \\
\text { you think about it because right now you think, oh } \\
\text { it's a pretty pond, but then after you hear that you } \\
\text { picture like piles of rubbish on the bottom and } \\
\text { everything. So it's just kind of like a weird picture. } \\
\text { It helps you picture things in two different ways } \\
\text { instead of having just one - the way it looks now. } \\
\text { V: Well it changes what we know because it's out } \\
\text { T: Shere where we can't see. } \\
\text { X: So you didn't know what? } \\
\text { T: We didn't know that- I didn't know that there were } \\
\text { like three different places that Cambridge gets its } \\
\text { water supply. }\end{array}$ & $\begin{array}{l}\text { Post-EcoMOBILE Observations: } \\
\text { R: So, it means that... } \\
\text { S: It's still higher but it went lower, but not super low. } \\
\text { R: There, dissolved oxygen is not in the water so the } \\
\text { fish and the plants can't survive. } \\
\text { A: ...the salt from like using to de-ice the roads and } \\
\text { stuff, and other contaminants, gets eventually gets } \\
\text { into the water and is all over the place and it's not } \\
\text { really good for you. And so they filter out through } \\
\text { the watershed. And the clean nice water goes into } \\
\text { the Fresh Pond and then we drink the water from } \\
\text { Fresh Pond. Yay! [Distant Impacts, time frame] } \\
\text { A: ...when you are exploring an ecosystem with an } \\
\text { EcoMobile time transporter tool? ...Uh, Um, } \\
\text { maybe if I went back, I could find out more about } \\
\text { if the-like, so in the video it said a lot about how } \\
\text { the trees were, like, there-there are less trees } \\
\text { and stuff and there's bittersweet everywhere } \\
\text { killing everything. Um, but I wonder what were } \\
\text { the water was like. I mean, she said that there was } \\
\text { a lot of sofas and stuff dumped into it, well, a } \\
\text { bunch of weird stuff dumped into the water, } \\
\text { but...yeah, and I also wonder if there's a lot of- } \\
\text { still as much animals. I doubt it, but I just wonder. } \\
\text { Hmm. (pause) Well, I didn't know that people tried } \\
\text { to, uh, fill up Black's Nook and I didn't know that } \\
\text { there were other nooks around here that were } \\
\text { filled up. And, that was kind of surprising to me. } \\
\text { Another thing that was surprising is that they } \\
\text { dumped a bunch of weird random stuff inside the } \\
\text { water in an attempt to fill it in. Obviously it didn't } \\
\text { work, but, um, yeah. } \\
\text { S: Look around and see- dig up things, see if there } \\
\text { are things there. } \\
\text { I mean also, you can kind of - you can see like how } \\
\text { some of the things sunk in so that- like that } \\
\text { happened. }\end{array}$ \\
\hline
\end{tabular}




\begin{tabular}{|c|c|c|c|}
\hline $\begin{array}{l}\text { A: } \\
\text { U: } \\
\text { A: } \\
\text { A: } \\
\text { U: } \\
\text { A: } \\
\text { U: }\end{array}$ & $\begin{array}{l}\text { being filled up and stuff. } \\
\text { Yeah, I didn't know about the surrounding nooks } \\
\text { either. } \\
\text { I didn't know stuff was planted here, I thought it } \\
\text { just grew wild. } \\
\text { And I didn't know there were odd objects like cars } \\
\text { and stuff. } \\
\text { Well, like, there's not a lot of stuff that's here from } \\
\text { back then, but like yeah that's a beech tree and } \\
\text { that's a beech tree. } \\
\text { Yeah, and you can tell that the trees have been } \\
\text { here for like a while. } \\
\text { Like definitely. So many of them are like huge. Like } \\
\text { that one that fell over and that one and that one. } \\
\text { I learned about um I think there's like a water } \\
\text { system that pours into like Fresh Pond. } \\
\text { Which is like go into Black? } \\
\text { It pours into...Well it comes into this whole area. } \\
\text { Mostly Fresh Pond. Some here too. So what does it } \\
\text { tell you about it? What does it...What are some } \\
\text { things that it might bring? } \\
\text { It might bring like bad stuff, and it might... } \\
\text { Like harmful things. } \\
\text { Yeah. } \\
\text { But the water is a little dirty mucky. } \\
\text { It's in the city, and it's not } \\
\text { Like cars. } \\
\text { Yeah, cars and like exhaust would be like poisons to } \\
\text { some animals. } \\
\text { I think that, um, the binoculars were very } \\
\text { interesting because they showed us an area that } \\
\text { we couldn't see, but with EcoMobile we could see, } \\
\text { and I thought it was interesting to see parts of land } \\
\text { that I wouldn't originally have seen. }\end{array}$ & $\begin{array}{l}\text { S: } \\
\text { C: } \\
\text { X: }\end{array}$ & $\begin{array}{l}\text { You could ask people. } \\
\text { Yeah, you could ask people. } \\
\text { Hm, like you might- do you have any ideas who } \\
\text { you might ask? } \\
\text { Like someone who's lived in Cambridge for a long } \\
\text { time. } \\
\text { And lives near here. ...Cause they know how it's } \\
\text { been. } \\
\text { Because it was before- because we haven't been } \\
\text { around here a long time to tell, you know? ...I } \\
\text { didn't know what they tried to fill it in. } \\
\text { I didn't know, either- and I didn't know that it was } \\
\text { basically a trash hole. } \\
\text { I didn't know it was a military place, either. } \\
\text { I did not know that. I didn't know it was a military } \\
\text { place. I did know a lot of the history of Black's } \\
\text { nook, and- } \\
\text { I didn't. } \\
\text { Yeah, me neither. I thought it was always like a } \\
\text { healthy, thriving place. } \\
\text { I know, right? } \\
\text { Right? But actually, people have put a lot of effort } \\
\text { into that. I might- I just- I'm thankful to that... } \\
\text { cause like, we wouldn't have this beautiful place } \\
\text { to go like running and stuff, right? } \\
\text { I learned a lot about the history of the pond. You } \\
\text { know, before I thought it was a thriving, you know, } \\
\text { ecosystem but it turns out that the gardening club } \\
\text { have been doing a lot of work to help out- keep } \\
\text { this ecosystem running because there are lot of } \\
\text { things that have stopped the ecosystem from } \\
\text { working and things- plants have died. But, you } \\
\text { know, over the past } 60 \text { years they've made an } \\
\text { effort to kind of help the ecosystem thrive. And } \\
\text { also I did not know anything about the history- } \\
\text { like I didn't know that they used this pond as a } \\
\text { trash hole. I also didn't know that there was a } \\
\text { cabin here....that they used it for military. I mean, } \\
\text { that's just really interesting to me. }\end{array}$ \\
\hline
\end{tabular}

